\title{
GÊNERO, CORPO E SEXUALIDADE: NEGOCIAÇÕES NAS BRINCADEIRAS DO PÁTIO ESCOLAR
}

\author{
ILEANA WeNETZ*
}

\begin{abstract}
RESUMO: A partir das vertentes dos estudos culturais e de gênero, pretendo problematizar como são atribuídos/constituídos/atravessados significados de gênero nas práticas corporais vivenciadas pelas meninas e pelos meninos. Indago como o corpo, as práticas corporais e as brincadeiras acontecem no pátio escolar. Realizei um estudo etnográfico durante um ano numa escola pública de Porto Alegre (RS), focalizando turmas da primeira a quarta séries, mapeando brincadeiras e negociações de gênero e de sexualidade que, inscritas nos corpos das crianças, possibilitam disciplinamento/resistências. Argumento que acontece uma aprendizagem não intencional no espaço do recreio, através da qual crianças aprendem a ser meninos e a ser meninas de um determinado jeito, legitimando uma única maneira em detrimento de outras.
\end{abstract}

Palavras-chave: Gênero. Sexualidade. Brincadeiras.

GENDER, BODY AND SEXUALITY: NEGOTIATIONS IN THE SCHOOLYARD GAMES

ABSTRACT: From the strands of cultural and gender studies, I intend to discuss how the meanings of gender are provided/set up/ crossed in bodily practices experienced by girls and boys. I question how the body, bodily practices and games take place in the schoolyard. I conducted an ethnographic study over one year at a public school in Porto Alegre, focusing on grade one to four,

Doutora em Ciências do Movimento Humano e participante dos Grupos de Estudos Socioculturais em Educação Física (Gesef) e do Grupo de Estudos em Educação e Relações de Gênero (Geerge/Faced), ambos da Universidade Federal do Rio Grande do Sul (UFRGS). E-mail: ilewenetz@gmail.com 
mapping games and negotiations of gender and sexuality, which inscribed on the children's bodies, allow discipline/resistances. I argue that an unintentional learning happens in playground space, through which children learn to be boys and girls of a certain way, legitimizing one way over others.

Key words: Gender. Sexuality. Games.

\section{Para começar...}

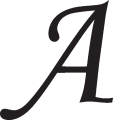

possibilidade de refletir sobre questóes relacionadas ao gênero corresponde a uma série de questionamentos sobre os quais me debruço neste artigo. ${ }^{1}$ Orientada inicialmente por estas dúvidas, procuro, a partir das vertentes dos estudos culturais e de gênero que se aproximam do pós-estruturalismo de Foucault (2002a, 2002b), entender como são produzidos e reproduzidos os significados de gênero que atravessam ou instituem modos diferenciados de ser menino e de ser menina num contexto particular: o recreio escolar. Assim, tendo como objeto de estudo as brincadeiras que acontecem neste contexto, pergunto: Quais são os significados sociais atribuídos ao corpo e ao gênero nas práticas corporais que permeiam o recreio de primeira a quarta séries de uma escola pública de Porto Alegre? Esta questão central foi dividida em algumas perguntas específicas: Como e o que as crianças aprendem sobre feminilidades e masculinidades, brincando no recreio? Que significados meninas e meninos conferem, concedem, consentem em relação a essas aprendizagens? Como o corpo torna-se alvo de determinados discursos que evidenciam algumas representações em detrimento de outras? Como as práticas corporais vivenciadas no recreio disciplinam corpos de meninos e meninas, generificando-os?

Em busca de pistas para responder essas questōes, realizei um trabalho etnográfico em que procurei problematizar as aprendizagens que acontecem nesse espaço, identificando, nele, os diferentes discursos que evidenciam algumas representações de gênero em detrimento de outras. Isso foi realizado entendendo que mesmo as brincadeiras, as falas, as disputas e as diversas ações que se realizam num espaço considerado tradicionalmente como espontâneo e livre carregam significados que as crianças produzem, atribuem e disputam a partir do meio social em que se encontram. 
Foi realizado, então, por um período de um ano, um processo de investigação que incluiu os diferentes momentos da rotina da escola (entrada e saída das crianças, atividades em sala de aula, passeios, hora do lanche e festas escolares) e também atividades extraordinárias, como as festas de aniversário de algumas crianças e os passeios que ocorreram fora do universo escolar. ${ }^{2}$ A opção por esse tipo de estudo está fundamentada na sua característica de se constituir num processo de observação que possibilita uma descrição detalhada de um contexto particular. Porém, com a intenção de investigar no lugar e não o lugar, observei as relações de gênero que ocorriam na escola e no recreio; da mesma forma, as análises que foram efetuadas também não se concentraram nos sujeitos e em suas falas, mas sim nos discursos e nas representações que davam sentido às suas falas e nas relações que os constituíam como sujeitos masculinos e femininos.

\section{A construção do/s gênero/s e da/s sexualidade/s no recreio}

Diferentes estudiosas da área consideram que o gênero se amplia para além da noção de papéis sociais, ${ }^{3}$ abrangendo todas as formas de uma construção social, cultural e linguística, dentro das quais se diferenciam homens e mulheres, incluindo seus corpos (Nicholson, 2000; Louro, 2000; Meyer, 2001, 2003). Essa perspectiva permite ampliar as análises e possibilita refletir, indagar e problematizar sobre o modo como determinadas posições atribuídas a mulheres e homens são produzidas como se fossem designios naturais.

Essas características diferentes interagem com a escola, modificando-se com o passar do tempo, e nem sempre deixam as mesmas marcas. Entendo as marcas como características (corporais ou não) que ficam inscritas nos sujeitos. Segundo as ideias de Louro (1997, p. 74), a escola, sob novas formas, continua imprimindo sua "marca distintiva" sobre os sujeitos. "Através de múltiplos e discretos mecanismos, escolarizam-se e distinguem-se os corpos e as mentes" (p. 62), procurando um sujeito disciplinado e organizado.

Os mecanismos que se observam podem ser muitos e variados: a própria organização da escola por idades, classes sociais, conteúdos e currículo determina um tipo de controle. Mas também podemos identificá-los nos desenvolvimentos das conversas informais, no que cada 
Gênero, corpo e sexualidade: negociações nas brincadeiras do pátio escolar

aluno/a aprende sobre o que pode e não fazer na escola, os movimentos ou jogos que pode realizar, como fazer e onde fazer. Todas essas características encontram-se inseridas na cultura da escola. Como entende Louro $(2001$, p. 81 ), "a sexualidade está na escola porque ela faz parte dos sujeitos, ela não é algo que possa ser desligado ou algo do qual alguém possa se "despir".

Esse fato poderia ser considerado paradoxal porque, apesar das possibilidades de interação que se colocam entre o professor e o aluno nas atividades do dia a dia, não há uma aceitação do próprio corpo dentro do espaço da escola. Em atividades como jogos, danças, esportes, entre outras, que permitem uma maior expressão do/a aluno/a, uma gestualidade própria fica em evidência, e medos ou dificuldades de lidar ou mostrar o próprio corpo podem ser trabalhados e observados, tanto no momento da aula quanto durante o recreio. Como reflete Narodowski (1994, p. 45), "o corpo na escola não é criativo; não ocupa um lugar relevante; é censurado; está, enfim, desprezado”.

Além desses aspectos, existe uma intencionalidade em que movimentos, gestos e expressões se concretizam. Segundo Louro (2001, p. 61), "gestos, movimentos, sentidos são produzidos no espaço escolar e incorporados por meninos e meninas, tornam-se partes de seus corpos. Ali se aprende a olhar e a se olhar, se aprende a ouvir, a falar e a calar; se aprende a preferir". E como isso ocorre no recreio da escola?

Essas exigências sociais que se estabelecem através de mecanismos de poder colocam-se também para meninos e meninas dentro do espaço do recreio, o que se confirmou no estudo desenvolvido, de acordo com o qual, além de configurar a sua organização, o gênero atravessa as próprias brincadeiras das crianças. No pátio, aconteciam simultaneamente diferentes brincadeiras e práticas esportivas, como voleibol, basquete, futebol, pular corda, elástico, ${ }^{4}$ pega-pega, jogos de mãos e danças. $\mathrm{Na}$ maioria das vezes, o basquete e o futebol eram praticados pelos adolescentes de gênero masculino, enquanto o voleibol era jogado pelas meninas adolescentes ou em grupos mistos. Os jogos de mãos e as danças eram as atividades preferidas das meninas da primeira à quarta série, enquanto os seus colegas meninos - da mesma idade - brincavam de lutas ou jogavam futebol.

Assim, observarmos que o recreio escolar está vinculado a diversas formas de controle/regulação sobre o corpo infantil (Foucault, 2002), em 
que diversos mecanismos contribuem para uma construção/conformação de meninas e de meninos, agindo no sentido de produzir uma imagem feminina ou masculina. Aqui, vemos as pedagogias culturais (Steimberg, 2001) e outras instâncias sociais, que, de diferentes modos, atuam na construção de meninos e meninas como possuidores de diferentes características. O gênero e a sexualidade no recreio podem ser observados através da constituição dos próprios grupos e de suas brincadeiras.

Para refletir sobre esse assunto, escolhi situações referentes a duas turmas que apresentavam características particulares: uma segunda série e uma terceira série. $\mathrm{Na}$ terceira série, observei uma vinculação específica das brincadeiras com o gênero que também acontecia com os meninos. João 5 gostava de brincadeiras consideradas tipicamente femininas, como elástico, pular corda, pega-pega e vôlei. Nunca brincava de futebol, sempre ficava com as meninas e não realizava nenhuma atividade com os meninos, nem na sala de aula, nem fora dela. Usava roupas tipo surfista, fazia luzes nos cabelos e os arrumava com gel. Por estas razões, ele recebia o apelido de "bicha" por parte dos colegas meninos e de crianças de outras séries também. Isso era tão corriqueiro que observamos várias situaçôes em que ele era chamado assim, inclusive por um estagiário da escola: "Olha o jeito que ele caminha", disse ele, ao tentar justificar o apelido que era dado ao João. Neste contexto, a prática do futebol parecia ser colocada quase como uma obrigação para um menino; não fazer o que se esperava de um menino levava-o a ser classificado como desviante. Análise semelhante foi desenvolvida em uma escola primaria de Londres, onde Swain (2006) também observou como o corpo é "docilizado" e como este mecanismo atuava através do futebol.

As próprias falas das crianças permitem observar a instauração de uma norma de linguagem que pode atuar de maneira repetida sobre a sexualidade e o gênero das crianças, operando como uma produção de identidades. Por exemplo, Janaína enuncia que "as meninas de outras turmas que chamam ele [João] de bicha, [é] só porque ele anda com menina”. Mas Janaína diz que ele pode brincar do que ele quiser, desde que não queira namorar homem: "O João não tem que se importar se ele quiser andar com menina. Ou ele quer namorar homem? Não, né?!”. Nessas falas, podemos observar como João era visto pelas meninas: elas o aceitavam e concordavam que ele brincasse com elas, mas entendendo que ele deveria manter sua heterossexualidade. 
Gênero, corpo e sexualidade: negociações nas brincadeiras do pátio escolar

Em relação a estes aspectos, outros exemplos relacionavam-se, vinculados a colegas da mesma turma de João. No primeiro caso, temos Pedro, que dançava balé fora do período da escola, mas no horário escolar só brincava de futebol e pertencia a um grupo de colegas composto só por meninos. Como ele era um menino que fazia as coisas que um menino deveria fazer, quase ninguém o importunava, apesar de os outros saberem que ele praticava balé. Além disso, se alguém o provocasse verbalmente (eventualmente, ele era incomodado por dançar balé), ele respondia com agressóes, correspondendo ao comportamento aguerrido usualmente esperado/caracterizado como masculino.

$\mathrm{E}$ o que acontece com outras crianças que atravessam as fronteiras de gênero, como as meninas que brincam de futebol? Nesse caso, perguntamos a Aline se alguém a aborrecia por ela preferir jogar futebol com os meninos, e ela respondeu que não. A maioria das crianças reconheceu que não a provocavam, mas, segundo Brenda, "às vezes os meninos pegam no pé dela, [dizendo] que ela é meio menino (...) que ela tem jeito de menino, até a voz dela, falam que é de menino; ela quer jogar bola e nunca vai brincar com as meninas de pular corda”. Apesar deste relato, apelidar as meninas ao se referir à sua sexualidade nunca foi presenciado por mim em campo, o que leva a considerar que, se acontecia, era de uma forma bem mais sutil e difusa do que no caso dos meninos. Isso parece ter sido estabelecido para não desequilibrar a hegemonia da heterossexualidade e a dicotomia tradicional homem-mulher.

Esses exemplos desarranjam tanto a fixidez da feminilidade e da masculinidade, apresentadas com artigo definido singular (a menina e o menino), quanto a narrativa hegemônica da dominação masculina e da subordinação feminina per se. Tal desarranjo também vem sendo visibilizado em outras situaçóes, como a de que as redes de vigilância e controle do gênero e da sexualidade parecem estreitar-se mais, contemporaneamente, em torno dos corpos masculinos, quando se trata de cruzamentos ou borramentos de fronteiras historicamente instituídas para a masculinidade heterossexual.

Nesse sentido, o corpo é entendido como resultado sempre temporário e instável de diversas configurações através dos tempos, adquirindo diferentes significados, mas configurado em e pelas redes de poder. Segundo Fraga (2000, p. 98), esse poder não "emana de nenhuma instituição ou indivíduo e muito menos se estabelece pelo uso da força, 
mas sim pela sutileza de sua presença nas práticas corporais $^{6}$ da vida cotidiana".

Em nossos dias e em nosso cotidiano, o corpo tornou-se lugar de identidade. Segundo Goellner (2003), o culto ao corpo que hoje vivenciamos começou a ser configurado no início do século XVIII, intensificando-se no século seguinte. A partir desse momento, teve uma maior centralidade, formando-se uma "moral das aparências que faz convergir o que se aparenta com o que efetivamente é" (Goellner, op. cit., p. 33). Sant'Anna (2000, p. 52) entende que "o corpo é algo que se adquire, se conquista, se constrói”, uma vez que se encontra em contínua modificação. Dessa forma, podemos entender que as aparências físicas nunca estão prontas, embora jamais estejam no rascunho.

Observei ainda como os meninos - ao mesmo tempo em que precisam, constantemente, provar que são machos e cavalheiros - precisam também provar que não são covardes. Assim, eles entendem que um menino deve ser cavalheiro com as meninas, mas também rebelde e bagunceiro: "Nós somos cavalheiros: não falamos para a professora o que elas fazem em nós" (Igor); Ser cavalheiro é "não bater em menina” (Diego); "se a menina tem um lápis pequeno, emprestar um grande que o menino tem" (Igor); "ser educado" (Diego). Eles mesmos percebem a oposição de suas atitudes: "Mas menino, na realidade, também é bagunceiro" (Diego).

Já as meninas não querem ser santas, mas também não querem ser reconhecidas como barangas. Sobre não ser santa, elas justificam afirmando que batem nos meninos. Quando perguntada se os meninos batem muito nela, Érika respondeu (rindo): "Não, porque a gente bate neles primeiro". Júlia reconheceu: "Eles batem na gente, mas às vezes a gente dá uma batidinha neles". Nas situações de conflito, meninos e meninas são chamados por apelidos. $\mathrm{O}$ apelido que as meninas mais recebem é o de baranga (mulher feia), o que as leva a responder batendo nos meninos ou os chamando por outros apelidos: "os colegas me imitam e me chamam de baranga" (Amanda); "quando a gente brincava de meninas pegarem os meninos, às vezes nos chamavam de barangas" (Mariana). Já o apelido que os meninos mais recebem é de gay. O exemplo adiante (diário de campo) mostra este tipo de situação, vivida por mim na pesquisa:

Karine, uma menina que poderia ser definida (tanto pela professora, como pelos pesquisadores) como uma menina meiga, que sempre cuida da aparência e vive passando batom, estava sentada num banco, ao meu 
lado. Perto dela, Braian implicava, chamando-a de "baranga". Ela ficou calada, olhando para mim - acho que esperava que eu xingasse Braian, mas isso não aconteceu. Então perguntei: "Que significa baranga?". Karine respondeu: "Mulher feia". Indaguei: "E por que ele te chama assim?”. Karine: "Porque ele é gay".

A resposta de Karine parece não fazer muito sentido, pois qual seria a relação entre apelidar alguém de gay, após ter sido chamada de feia? A resposta encontra-se na generificação destas acusações: chamar Braian de gay serviu como uma acusação com um caráter tão pejorativo quanto o apelido que Karine recebeu (mulher feia). Esse aspecto reforça a dimensão pejorativa de ser gay, ou seja, da homossexualidade, vinculada aos meninos.

Considerando as falas destacadas, é possível observar como alguns pressupostos de masculinidade e de feminilidade se constituem como noções homogêneas e universais, como dados desde sempre dessa maneira. Mas também pudemos salientar as diferentes configuraçōes que se desenham, se reconfiguram e se ressignificam constantemente, sendo alvos de disputas no espaço do recreio. Enfatizando dois dos desdobramentos de gênero (seu caráter relacional e sua intersecção com outros marcadores sociais, como a sexualidade, por exemplo), posso argumentar que os mesmos discursos que produzem meninos como agressivos, cavalheiros ou covardes produzem as meninas como meigas, quietas ou "barangas". Assim, múltiplas identidades, nem sempre harmônicas e convergentes, são constituídas simultaneamente em processos educativos não formais.

\section{Considerações finais}

Neste artigo, problematizei algumas concepções entendidas como naturais nas articulações de gênero com sexualidade, em um espaço específico, para definir um modo de ser menino e de ser menina. Observar/mapear essas complexidades permitiu-me desnaturalizar algumas concepções subjacentes à construção de masculinidades e feminilidades em vários espaços e processos, entre eles um que parece inusitado à primeira vista: o recreio escolar.

Observei que o recreio é um espaço generificado e sexualizado. Nele, as crianças não são tão livres quanto poderíamos acreditar. Elas não 
brincam todas juntas, não fazem sempre o que querem, nem todas brincam em todos os espaços e, ainda, nem todas brincam do que gostariam. As brincadeiras são generificadas e sexualizadas e ocupam diferentes espaços no pátio. Tais espaços são disputados, negociados ou impostos.

Destaco, ainda, que a escola não se constitui um lugar homogêneo e harmônico, e a presente investigação permitiu que isso fosse visualizado. Ela é uma instituição na qual se disputam, se aceitam, se rejeitam e se impóem significados através de processos em que as crianças se encontram inseridas, participando de negociaçôes culturais ou imposições muito complexas, que acontecem, também, nas brincadeiras do pátio escolar.

\section{Notas}

1. Este artigo se desprende da minha pesquisa de mestrado intitulada Gênero e sexualidade nas brincadeiras do recreio (2005), apresentada na Escola Superior de Educação Física (UFRGS).

2. Além da observação direta em todo o contexto da escola, fiz uso da observação participante (Becker, 1997; Knauth, Ceres \& Stigger, 2002) focalizada no recreio e nas brincadeiras que ali ocorriam. Neste universo, através da "bola de neve" (Taylor, 1996), realizei conversas informais com diversas crianças, assim como com diferentes pessoas da comunidade escolar; além disso, realizei entrevistas com 58 crianças.

3. Para aprofundar a crítica realizada ao conceito de papéis, ver Louro (2001).

4. Brincadeira que consiste numa disputa de habilidades de saltos sobre uma corda elástica estendida por três ou quatro metros de distância.

5. Por questões éticas, os nomes das crianças são fictícios.

6. Defino as práticas corporais como qualquer expressão não só de caráter motriz, como as danças, as brincadeiras, a ginástica e os esportes, mas toda aquela que pode ser realizada por um sujeito, seja um movimento específico, uma fala, um gesto ou até um silêncio.

\section{Referências}

BECKER, S.H. Métodos de pesquisa em Ciências Sociais. São Paulo: Hucitec, 1997.

FRAGA, A.B. Corpo, identidade e bom-mocismo: cotidiano de uma adolescência bem-comportada. Belo Horizonte: Autêntica, 2000. (Coleção Trajetória).

FOUCAULT, M. Vigiar e punir. Petrópolis: Vozes, 2002a. 
Gênero, corpo e sexualidade: negociações nas brincadeiras do pátio escolar

FOUCAULT, M. Microfísica do poder. Rio de Janeiro: Edições Graal, $2002 b$.

GOELLNER, S.V. A produção cultural do corpo. In: LOURO, L.G.; NECKEL, J.F.; GOELLNER, S.V. (Org.). Corpo, gênero e sexualidade: um debate contemporâneo na educação. Petrópolis: Vozes, 2003.

KNAUTH, D.; CERES, V.; AGRA HASSEN, M. Pesquisa qualitativa em saúde. Porto Alegre: Tomo Editorial, 2000.

LOURO, G.L. A escola e a pluralidade dos tempos e espaços. In: COSTA, M.V. (Org.). Escola básica na virada do século. Porto Alegre: Faced/UFRGS, 1995.

LOURO, G.L. Corpo, escola e identidade. Educação \& Realidade, Porto Alegre, v. 25, n. 2, p. 59-76, jul./dez. 2000.

LOURO, G.L. Gênero, sexualidade e educação: uma perspectiva pósestruturalista. Petrópolis: Vozes, 2001.

MEYER, D. Cultura e docência teuto-brasileiro-evangélica no Rio Grande do Sul. Santa Cruz do Sul: Edunisc; São Leopoldo: Sinodal, 2000.

MEYER, D. Gênero e educação: teoria e política. In: LOURO, G.L.; NECKEL, J.F.; GOELLNER, S.V. (Org.). Corpo, gênero e sexualidade: um debate contemporâneo na educação. Petrópolis: Vozes, 2003.

NARODOWSKI, M. Cuerpo infantil y escolaridad moderna. Educação e a nova era. Reflexão, Campinas, v. 19, n. 58, p. 23-44, jan./abr. 1994.

NICHOLSON, L. Interpretando o gênero. Estudos Feministas, Florianópolis, v. 8, n. 2, p. 9-42, 2000.

SANT'ANNA, D. Descobrir o corpo: uma história sem fim. Educação \& Realidade, Porto Alegre, v. 25, n. 2, p. 49-58, jul./dez. 2000.

STEINBERG, S.; KINCHELOE, J. (Org.). Cultura infantil: a construção corporativa da infância. Rio de Janeiro: Civilização Brasileira, 2001.

STIGGER, M.P. Esporte, lazer e estilos de vida: um estudo etnográfico. Campinas: Autores Associados; Editorial Colégio Brasileiro de Ciências do Esporte, 2002. (Coleção Educação Física e Esportes). 
SWAIN, J. The role of sport in the construction of masculinities in English independent junior school. Sport, Education and Society, v. 11, n. 4, p. 317-335, nov. 2006. Disponível em: <http://www.emabs. sagepub.com>. Acesso em: 12 fev. 2008.

TAYLOR, S.J.; BOGDAN, R. Introducción a los métodos cualitativos de investigación. La búsqueda de significados. Barcelona: Paidós, 1996.

WENETZ, I. Gênero e sexualidade nas brincadeiras do recreio. 2005. Dissertação (mestrado em Ciências do Movimento Humano - Representações Sociais do Movimento Humano) - Escola Superior de Educação Física da Universidade Federal do Rio Grande do Sul, Porto Alegre.

Recebido em 5 de abril de 2011.

Aprovado em 30 de junho de 2012. 